\title{
IFRS Subjectivity: the Other Side of the Coin
}

\author{
Daniele Gervasio ${ }^{*}$, Damiano Montani \\ Assistant professor of International Accounting, Università degli studi di Bergamo, Bergamo, Italy \\ *Corresponding Author: daniele.gervasio@unibg.it
}

Copyright (C) 2013 Horizon Research Publishing All rights reserved.

\begin{abstract}
The study shows the benefits of more discretion and less guidance in IFRS by presenting an arbitrariness and subjectivity index. The measurement of discretion proposed is based on a scale of values which improves the accuracy of information on measurements, allowing stakeholders to understand independently the level of subjectivity inherent in any accounting items. The study illustrates the matrix format statement, in which retrospective and dynamic accounting results, based on historical cost and fair value are combined, associated with an "accounting discretion view". By highlighting the degree of accounting discretion, this approach provides users with a clear and realistic vision in which accounting choices or estimates can be credible signals of a firm's financial performance. Regulators and users of accounting information have to accept a limited subjectivity in pursuit of more informative financial reporting because results seem to suggest that discretion, in spite of all the opportunities to manipulate reported outcomes and mislead users, appears to add value: reasonable and legal management decision making and reporting tend to achieve stable and predictable financial results.
\end{abstract}

Keywords Matrix Format Statement, Accounting Subjectivity, Accuracy of Information

\section{Introduction}

In this work, we propose an alternative method for representing balance sheet data that is able to monitor, measure and classify the level of discretionary power inherent in the evaluation of each of the items in the balance sheet.

The annual balance sheet - with reference both to the profit and loss account and to the statement of assets and liabilities - actually presents a collection of accounting items that are extremely heterogeneous, including the way in which they are determined.

In fact, each accounting item may derive from a "sure" base (for example the balance of a current account), or on the contrary, may be founded on values conjectured by the balance sheet compiler: this is the case, for example, of depreciations, devaluations and, in general of "fair value" assessments.

The presence of an evaluation activity, based on the discretionary power of the compiler of the balance sheet, is at one and the same time both a vital requisite and an element of risk in drawing up the annual balance sheet:

$\rightarrow$ it is indispensable because without the evaluation activity, the balance sheet would be nothing but the statement of account of a series of financially "certain" elements, without the possibility to explain the activity carried out by the company with regard to the accrual basis or the future prospects of the same (for international accounting principles, the evaluations of a dynamic nature, based essentially on "fair value");

$\rightarrow$ it represents an obstacle to a true and correct representation of the company's accounting data insofar as it is based mainly on the sensitivity (or, in pathological cases, on the undeclared aims) of the balance sheet compiler.

The discretionary power in evaluation is, therefore, subject potentially to operations of "earnings management", because of the very subjectivity of the balance sheet evaluations.

\section{Studies in Literature Connected with "Earnings Management"}

In order to better understand the need to monitor the level of subjectivity in the assessment of financial statement it is necessary to first make a digression concerning "'earnings management".

Literature has dealt widely with the phenomenon of "earnings management", in the sense of an abuse of the discretionary power in evaluation on the part of the balance sheet compiler for the purpose of subjugating the accounting data to their own ends.

The problem of balance sheet policies and the related alteration of the accounting evaluations has assumed such proportions and importance over the last few decades that it has attracted the attention of the international scientific community.

"Earnings management" has been defined as [1] "the management of information", understood as an intentional intervention in the process of financial reporting aimed at 
the external users of the company, in the aim of achieving personal interests, whatever they may be.

The consequence of the "earnings management" is the so-called "smoothing", understood as a reduction or "levelling" of the variations in the accounting data over time.

As from the 1960s [2] a conviction developed amongst experts on an international level that the more promising the information was regarding the profits shown in the financial year balance sheet, the more positive was the markets' reaction.

From this derived the managers' keenness to mention income results in their periodic communications (and, consequently, the financial results and the statement of assets and liabilities) that were at least equal or above the expectations expressed by the market.

Consequently, a dangerous combination of factors can be sensed:

$\rightarrow$ a class of stakeholders appointed to draw up the balance sheet (managers or directors) which possesses all the accounting and operational information regarding the company and is able to exclude all the other stakeholders (with the exception, in part, of the auditors) from consulting such data;

$\rightarrow$ in preparing the annual balance sheet, managers alone handle the accounting data and adjust them in order to calculate the income for the financial year, applying technical discretionary power attributed to them and which is essential in order to perform correct evaluations;

$\rightarrow$ technical discretionary power is attributed to a class of stakeholders with their own individual interests, which, as such, cannot act neutrally towards the other stakeholders: therefore, there may be some justification for thinking that this group of subjects can use the information that it alone possesses for its own benefit;

$\rightarrow$ the evaluation choices put into effect by the administrators in virtue of the technical discretionary power attributed to them, are rarely contested by the other stakeholders: in fact, the evaluations are made according to accounting regulations which apart from being complex, are also based on the sensitivity and honesty of the balance sheet compiler, and hard to confute [3].

Burgstahler and Dichev identify two possible reasons for "earnings management":

$\rightarrow$ the "need" to report positive information in order to minimise the transaction costs with the stakeholders;

$\rightarrow$ the aversion to absolute or relative losses, that is in any case inherent in the management.

However, further reasons may be identified [4]:

$\rightarrow$ the managers' interest in obtaining the remuneration promised to them on the basis of the income results;

$\rightarrow$ their wish to make their job more secure;

$\rightarrow$ the need to reduce the risk of penal sanctions linked to the violation of financing contracts;

$\rightarrow$ the fear of interventions by regulatory bodies (e.g. for proceedings with the participation of more than one claimant or for the rules of the capital market); $\rightarrow$ the aim of concealing a transfer of wealth from one class of stakeholder to another [5].

Furthermore, a tendency has been noted [6] among managers dealing in the context of the U.S. GAAP regulation to take advantage of the considerable discretionary power conceded to them by the accounting principles regarding the choice of the evaluation procedures.

In one of the milestones of «earnings management» theory, it is asserted that a statistic of between $30 \%$ and $44 \%$ of the companies with a debit balance in the income results made adjustments, within their discretionary evaluation powers, in order to make positive improvements to the incomes.

The operations on the profits were mainly singled out as manipulations of the cash flow, as alterations of the circulating capital (which had the advantage of not directly influencing the determination of the cash flow), by altering the research, development and advertising expenses or the timing of the fixed assets management [7].

Besancenot and Vranceanu showed that simulations and tax-evasion do not only occur in situations of financial difficulty, but, on the contrary, are frequent even in more prosperous companies where managers often have the tendency to overestimate their performance for the very purpose of benefiting from undeserved bonuses that the company can, in any case, afford to grant them.

Moreover, it can also be added that, from the study carried out [8], it would seem that a positive correlation has been perceived between the solidity of the companies and the bad faith of the details stated in the annual accounts. Standard setters have often been interested in establishing parameters that regulate the trade-off between discretionary powers and earnings management.

The presence of a trade-off becomes evident in the definition of «earnings management» given by Healy and Wahlen [9], when it is understood as that attitude of managers who use the discretionary powers bestowed on them and their judgement to modify accounting data, to deceive the other stakeholders regarding the economic performance of the company or to influence the possible contractual outcomes that depend on the accounting data.

The trade-off appears even more important if consideration is given to the fact that discretionary powers form a part of the discernment that is essential for managers to run the companies entrusted to them: if this were not the case, the managers would not have the instruments necessary for managing the company and their role would be totally pointless.

However, discernment represents the main root of the "earnings management" principle and, apparently, it can only be opposed by reducing or monitoring the discretionary powers and the subjective evaluation.

The incomes can be modified by moving the income components appropriately from one financial year to another (so-called "direct management" or "timing") or by employing "misreporting" [10] practices. 
Misreporting is identified with bad accounting management and involves the systematic violation of the evaluation procedures, with the complicity of the other people responsible for the accounts, or the modification of the information processes, so that the other people are kept in the dark.

As in the case of exaggeratedly precise rules, it has been shown [11] that when postulates are too wide and abstract they leave room for discretionary powers, encourage managers to take advantage of the wide gap left by the abstractness and discourage auditors (as they themselves are "confused" by the complication of the regulation) from intervening by sanctioning the managers' behaviour.

In any case, neither the production of specific rules nor the transfer to a accounts system based on general principles can tackle the main weak point of accounting which lies in the absolute and inevitable dependency on subjective evaluations. Consequently, an instrument is needed that is able to measure and show in the balance sheet the degree of discretionary powers involved in each accounts item.

\section{The Segregation of Accounts Items Subject to "Remeasurement": the "Matrix Format" Balance Sheet}

From the points made so far, it can be deduced that: $\rightarrow$ most of the "earnings management" phenomena occur when there is an abuse of the discretionary powers of evaluation granted, as a necessity, by the accounting principles to the balance sheet compilers;

$\rightarrow$ the "earnings management" phenomena include a wide range of more or less fraudulent operations for the purpose of modifying the perception that the stakeholders have of the accounts informations;

$\rightarrow$ the possibilities of altering the accounting data connected with "earnings management" increase in proportion to the complexity and the discretionary powers of the accounting evaluations: it follows that it is "simpler" to alter the accounting data based on international principles than when observing accounting principles based on historical cost and on the related principle of prudence;

$\rightarrow$ it has been shown [16 - $17-18]$ that the advent of international financial standard in countries where there was only the historical cost principle, has increased the use of earnings management: this suggest that "earnings management" has intensified with increasing editor's discretionary power.

It may be deferred that if the accounting items subject to greater discretionary powers of evaluation ("remeasurement") could be segregated and identified, the phenomenon of "earnings management" could be partly restrained.

To satisfy these needs, a new balance sheet format must be defined, that is able to separate the more objective accounting elements (that are "certain" or, at least based on historical costs), compared with those that are remeasured on conjectural bases, but without having to forego the informative capacity of a modern balance sheet based on "fair value".

To establish this ideal statement, it is necessary to draw simultaneously on the lengthy experience acquired by FASB, the new methods established by international Standard Setters and the analyses performed by the scientific community in recent years.

It is evident that the need to provide at least two values for each accounting item requires the balance sheet data to be displayed according to a matrix system.

In fact, IASB moved in this direction in the period 2001 2003 , in the framework of a joint project with the UK Accounting Standards Board (ASB) on "performance reporting".

The aim of the project was to catalogue and show all the income and costs for the period in order to allow the users to understand fully the company's performance.

The study suggested by the Standard Setters [12] and the doctrine [13] focused only on the income statement as the best method to achieve the purpose of standard setter, classifying the costs and the income in the profit and loss account for the financial year under the values "pre remeasurement" and "post remeasurement".

The so-called "matrix format income statement" has been studied in practice by Tarca and others [14] [15], whose studies are a milestone in the field.

The work drew inspiration from the matrix format income statement proposed by the IASB and the FASB, quickly shelved as it was considered confusing and misleading to apply in practice, both for user and preparers.

The purpose of Tarca's study was to demonstrate the benefits in terms of better information provided to readers, ability to extract the best information and to categorise and display all income and expenses for the period in a way that enhances users' understanding of the entity's financial results.

The studies conducted by Tarca et alii show that the multi-column income statement report has not damaged users' confidence, but, on the contrary, it improves the accuracy in the extraction of information from the financial statement.

Tarca concluded as follows: "Our findings suggest that adopting the matrix format would not pose a major educational challenge, at least when it comes to financial analysts, accountants and managers. Our experiment is a useful starting point for evaluating a matrix format for the reporting of comprehensive income.".

The work of standard setters and the literature cited, however, have paid attention only to the income statement: as its aim was to define and categorize the revenue and costs, segregating components subject to remeasurement, so as to obtain greater clarity with particular regard to the "comprehensive income".

The abandoned project of standard setter is here taken up and extended to the balance sheet; like the work cited above, 
the goal is to show the best quality of information provided by the matrix format, extending the benefits of the income statement matrix format to the balance sheet account.

The company's balance control based on the historical cost approach, adopted for the implementation of financial reporting of national budgetary frameworks, has always been based on the balance sheet's provisions instead of income statement's cash flows.

In such contexts, the activities of earnings management, as well as the issues of transparency in financial statements, have their focus of interest even more on the balance sheet rather than the income statement.

The balance sheet, in fact, reflects the discretionary assessments of income statement, returning each year evaluation errors, changes in the budget, or assessments that reflect the preparer's personal, subjective perspective..

In addition, fair value cause a second discretionary distortion which exacerbates earning management phenomena: so that, the reader of the financial statement needs data presented in a format that segregate and highlight all remeasured accounts.

In this contest, we try to show an example of application of the matrix format profit and loss (including the section "comprehensive income"), too hastily abandoned by standard setter: in fact, the matrix format also affects the balance sheet as fund of discretionary policy assessment.

In this case, the segregation operates on two levels, one "static", based on historical cost evaluations, and the other "dynamic", which includes the values at "fair value" and all the values that arise from discounted prospective results..

The scale of values is divided in the following way:

- Historical cost;

- remeasurement;

- Dynamic values

In addition, the example shows, differently to the draft proposed by the standard setters, the income statement widely streamlined, with a reduction of three columns.

\section{Case Study}

Here below we propose an operating structure of a balance sheet set out according to a "matrix format" project.

Let us suppose that the following account situation is given by the accounting records of a Company " $\mathrm{X}$ ": 
Table 1. The account stuation

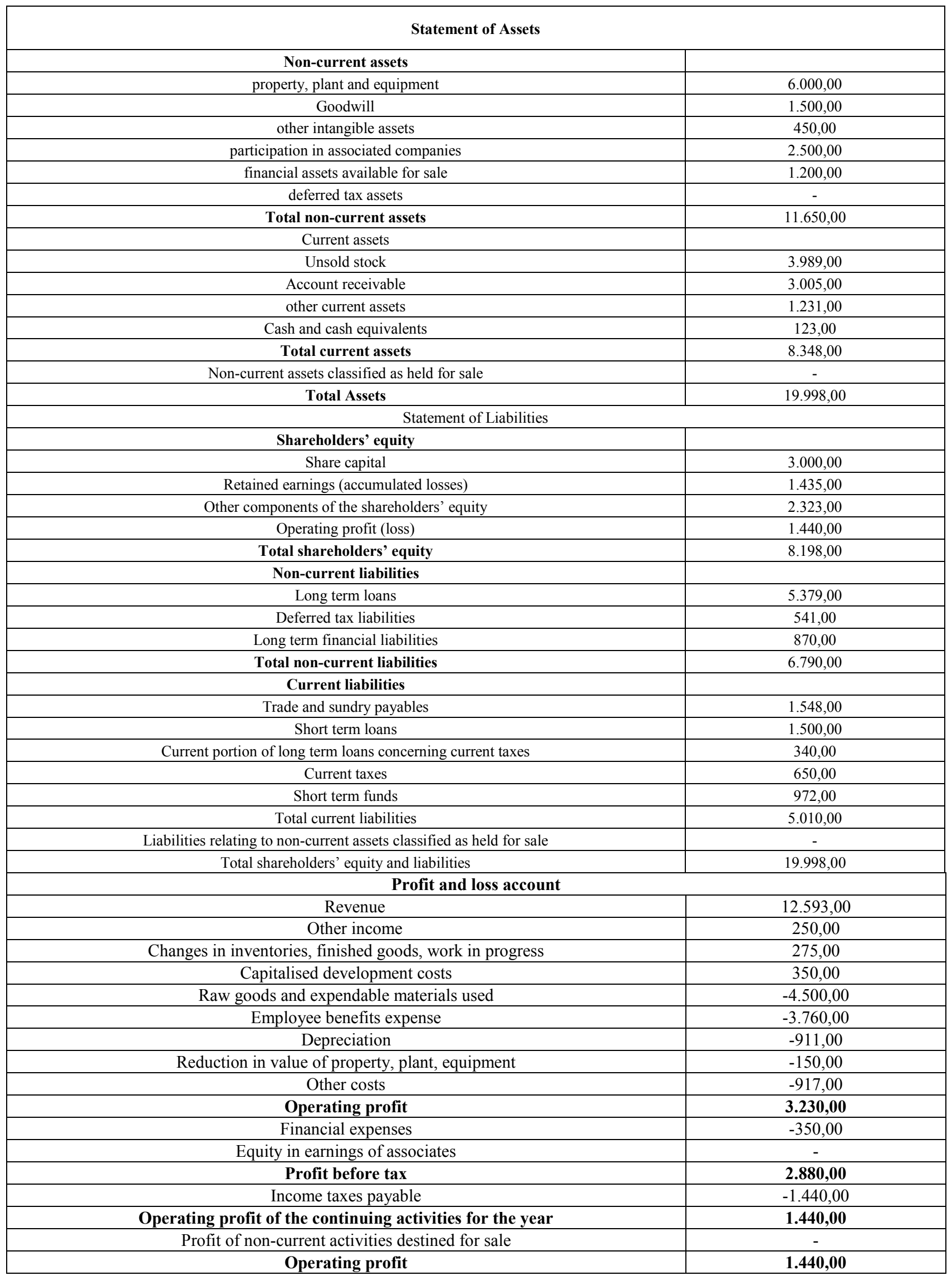


During evaluation, the following variations are made to bear in mind the potential prospective income components (the number of each adjustment operation, indicated below, corresponds to the number of the note at the side of the relevant accounting adjustment in the financial year balance sheet):

1. The historical cost relative to the item "Property, plant and equipment" is readjusted to the fair value, with an increase of 800 and a consequent increase of 80 in depreciation. The difference, equal to $800-80=720$ is not put to reserve, but straight into the profit and loss account

2. The financial liabilities for employee benefits are also included amongst the long term financial liabilities (non-current liabilities of the statement of assets and liabilities). The actuarial evaluation of this financial liability shows a profit of 50 , given by the negative variation in the actual value of the liability undertaken.

3. The "other current assets" include securities "held for trading" the estimated fair value of which exceeds the historical cost registered in the statement of assets and liabilities by 149 .

4. The item "depreciation" includes 300 for the depreciation of the goodwill. After performing the impairment test, it is held that said depreciation is not due, as it is estimated that the goodwill has lasted for an indefinite period. The depreciation already ascribed to the profit and loss account is cancelled.

5. The fair value of the "financial assets available for sale" exceed the historical value registered in the balance sheet assets by 375 .

6. The taxes estimated on the incomes of the "other components of the comprehensive profit and loss account" amount to 470 . The counter-item is allocated to the item "deferred tax liabilities".

7. Included amongst the "non-current assets" is the accounting item "hedging instruments" relative to an interest rate swap, equal to 72 .

The balance sheet in matrix format, rectified to take into account these adjustment operations calculated on the basis of dynamic methodologies, is as follows: 
Table 2. The matrix format project

\begin{tabular}{|c|c|c|c|c|}
\hline Statement of assets & Historical values & Remeasurement & $\begin{array}{l}\text { Dynamic } \\
\text { values }\end{array}$ & Notes \\
\hline \multicolumn{5}{|l|}{ Non-current assets } \\
\hline property, plant and equipment & $6.000,00$ & 720,00 & $6.720,00$ & 1 \\
\hline Goodwill & $1.500,00$ & 300,00 & $1.800,00$ & 4 \\
\hline other intangible assets & 450,00 & 0,00 & 450,00 & \\
\hline participation in associated companies & $2.500,00$ & 0,00 & $2.500,00$ & \\
\hline financial assets available for sale & $1.200,00$ & 375,00 & $1.575,00$ & 5 \\
\hline Hedging instruments & 0,00 & 72,00 & 72,00 & 7 \\
\hline deferred tax assets & 0,00 & 0,00 & 0,00 & \\
\hline Total non-current assets & $11.650,00$ & $1.467,00$ & $13.117,00$ & \\
\hline \multicolumn{5}{|l|}{ Current assets } \\
\hline Unsold stock & $3.989,00$ & 0,00 & $3.989,00$ & \\
\hline Account receivable & $3.005,00$ & 0,00 & $3.005,00$ & \\
\hline other current assets & $1.231,00$ & 149,00 & $1.380,00$ & 3 \\
\hline Cash and cash equivalents & 123,00 & 0,00 & 123,00 & \\
\hline Total current assets & $8.348,00$ & 149,00 & $8.497,00$ & \\
\hline Non-current assets classified as held for sale & 0,00 & 0,00 & 0,00 & \\
\hline Total Assets & $19.998,00$ & $1.616,00$ & $21.614,00$ & \\
\hline \multicolumn{5}{|l|}{ Statement of liabilities } \\
\hline Shareholders' equity & Historical values & Remeasurement & $\begin{array}{l}\text { Dynamic } \\
\text { values }\end{array}$ & Notes \\
\hline Share capital & $3.000,00$ & 0,00 & $3.000,00$ & \\
\hline Retained earnings (accumulated losses) & $1.435,00$ & 0,00 & $1.435,00$ & \\
\hline Other components of the shareholders' equity & $2.323,00$ & 0,00 & $2.323,00$ & \\
\hline Operating profit (loss) for the year & $1.440,00$ & $1.196,00$ & $2.636,00$ & \\
\hline Total shareholders' equity & $8.198,00$ & $1.196,00$ & $9.394,00$ & \\
\hline \multicolumn{5}{|l|}{ Non-current liabilities } \\
\hline Long term loans & $5.379,00$ & 0,00 & $5.379,00$ & \\
\hline Deferred tax liabilities & 541,00 & 470,00 & $1.011,00$ & 6 \\
\hline Long term financial liabilities & 870,00 & $-50,00$ & 820,00 & 2 \\
\hline Total non-current liabilities & $6.790,00$ & 420,00 & $7.210,00$ & \\
\hline \multicolumn{5}{|l|}{ Current liabilities } \\
\hline Trade and sundry payables & $1.548,00$ & 0,00 & $1.548,00$ & \\
\hline Short term loans & $1.500,00$ & 0,00 & $1.500,00$ & \\
\hline Current portion of long term loans concerning current taxes & 340,00 & 0,00 & 340,00 & \\
\hline Current taxes & 650,00 & 0,00 & 650,00 & \\
\hline Short term funds & 972,00 & 0,00 & 972,00 & \\
\hline Total current liabilities & $5.010,00$ & 0,00 & $5.010,00$ & \\
\hline $\begin{array}{l}\text { Liabilities relating to non-current assets classified as held for } \\
\text { sale }\end{array}$ & 0,00 & 0,00 & 0,00 & \\
\hline Total shareholders' equity and liabilities & $19.998,00$ & $1.616,00$ & $21.614,00$ & \\
\hline
\end{tabular}




\begin{tabular}{|c|c|c|c|c|}
\hline Profit and loss account & $\begin{array}{l}\text { Economic values } \\
\text { realised }\end{array}$ & $\begin{array}{c}\text { Remeasurement } \\
\text { (Income components } \\
\text { not realised) } \\
\end{array}$ & $\begin{array}{c}\text { Dynamic } \\
\text { income } \\
\text { values } \\
\end{array}$ & Notes \\
\hline Revenue & $12.593,00$ & 0,00 & $12.593,00$ & \\
\hline Other income & 250,00 & 149,00 & 399,00 & \\
\hline Changes in inventories, finished goods, work in progress & 275,00 & 0,00 & 275,00 & \\
\hline Capitalised development costs & 350,00 & 0,00 & 350,00 & \\
\hline Raw materials and expendable materials used & $-4.500,00$ & 0,00 & $-4.500,00$ & \\
\hline Employee benefits expense & $-3.760,00$ & 0,00 & $-3.760,00$ & \\
\hline Depreciation & $-911,00$ & $-80,00$ & $-991,00$ & \\
\hline Reduction in value of property, plant and equipment & $-150,00$ & 0,00 & $-150,00$ & \\
\hline Other costs & $-917,00$ & 0,00 & $-917,00$ & \\
\hline Operating profit & $3.230,00$ & 69,00 & $3.299,00$ & \\
\hline Financial expenses & $-350,00$ & 0,00 & $-350,00$ & \\
\hline Equity in earnings of associates & 0,00 & 0,00 & 0,00 & \\
\hline Profit before tax & $2.880,00$ & 69,00 & $2.949,00$ & \\
\hline Income taxes payable & $-1.440,00$ & 0,00 & $-1.440,00$ & \\
\hline Profit for the year of the continuing operations in the period & $1.440,00$ & 69,00 & $1.509,00$ & \\
\hline Profit from the non-current assets destined for sale & 0,00 & 0,00 & 0,00 & \\
\hline Operating profit & $1.440,00$ & 69,00 & $1.509,00$ & \\
\hline \multicolumn{5}{|l|}{$\begin{array}{l}\text { Other components of the comprehensive profit and loss account } \\
\text { (other comprehensive income) }\end{array}$} \\
\hline $\begin{array}{l}\text { Differences in the exchange rate deriving from the conversion of the } \\
\text { balance sheets managed abroad }\end{array}$ & & 0,00 & 0,00 & \\
\hline $\begin{array}{l}\text { Profit (loss) from recalculation of value of financial assets available for } \\
\text { sale }\end{array}$ & & 375,00 & 375,00 & 5 \\
\hline Profit (loss) from hedging instruments & & 72,00 & 72,00 & 7 \\
\hline \multirow{2}{*}{ Revaluation of property, plant and equipment and intangible assets } & & 800,00 & 800,00 & 1 \\
\hline & & 300,00 & 300,00 & 4 \\
\hline Actuarial profit (loss) from defined benefit plans & & 50,00 & 50,00 & 2 \\
\hline $\begin{array}{l}\text { Quotas of other components of the comprehensive profit and loss } \\
\text { account concerning associates }\end{array}$ & & 0,00 & 0,00 & \\
\hline $\begin{array}{l}\text { Income tax relative to the other components of the comprehensive profit } \\
\text { and loss account }\end{array}$ & & $-470,00$ & $-470,00$ & 6 \\
\hline $\begin{array}{l}\text { Total of the other components of the comprehensive profit and loss } \\
\text { account after taxes }\end{array}$ & & 0,00 & 0,00 & \\
\hline Total comprehensive income for the operating year & $1.440,00$ & $1.196,00$ & $2.636,00$ & \\
\hline
\end{tabular}

Comments on the adjustments.

1. As a consequence of the adjustment of the item "Property, plant and equipment" to the fair value of the historical cost, in the matrix format of the statement of assets and liabilities, an increase equal to 720 is shown in the second column (given by the difference between the greater value calculated at fair value, reduced by the greater depreciation calculated on the difference). Therefore, in the matrix format of the profit and loss account, a greater depreciation equal to 80 is added in the second column of the accounting item "depreciation", while in the accounting item "Profit (loss) from recalculation of the value of financial assets available for sale" a surplus of 800 is added that has not been realised.

This surplus is added in the comprehensive income statement as: $\rightarrow$ it has not yet been realised;

$\rightarrow$ it refers to a non-current capital asset.

2. The non-current liability for the pension fund, estimated at fair value on the basis of an actuarial calculation, shows a reduction of 50, which reduces the liability from 870 to 820 .

The reduced liability presents, as a counter-item, a profit which, as coming from an evaluation, has not yet been realised; as it refers to a non-current balance sheet element, the profit is registered amongst the components of the comprehensive income directly in the second column of the profit and loss account, thus influencing only the income components referring to dynamic evaluations.

3. The adjustment to fair value of the securities "held for trading" leads to an increase in the value of the shareholders' equity to be entered in the second column of the statement 
of assets and liabilities.

In the counter-item, in the second column of the profit and loss account, a surplus is shown on securities (which, for simplicity, in this example is added to the item "other income"). It concerns a profit which has not yet been realised, but regards current balance sheet elements and, therefore, it is not added to the "other items of comprehensive income", but directly amongst the items of the profit and loss account.

4. The net accounting value of the goodwill, depreciated by 300 according to the static methods of evaluation, stood, as of 31-12-n at 1500, including the depreciation referred to financial year $n$.

Following the ascertainment of the permanency of the value by means of the impairment test, it is believed that the useful life of this balance sheet element is still intact and can be projected into the future for an indefinite period, and so a decision is taken to cancel the depreciation carried out.

An increase in value equal to 300 is entered in the second column of the statement of assets and liabilities; in the same way, amongst the "other components of the comprehensive income" a positive income component that has not yet been realised equal to 300 is noted and refers to a non-current element of the assets

5. This concerns a revaluation of non-current assets and refers in particular to securities " held for trading". The entry of the greater value in the second column of the assets of the balance sheet occurs as a counter-item of the surplus not yet realised, recorded amongst the "other components of comprehensive income".

6. The allocation of the taxes concerning the "other components of comprehensive income", occurs in the same section of the incomes to which they refer and leads to the entry in the statement of assets and liabilities of a non-current liability.

7. The historical cost regarding the interest rate swap, as in the first column of the assets of the statement of assets and liabilities, is equal to zero: in fact, the possible payment of the premium does not occur at the undersigning of the contract, but only when the commitment to pay the difference between the variable interest rate and the rate pre-set in the contract must be honoured.

The fair value of the hedging instrument is equal to 72 : this evaluation depends on the fair value of the hedging instrument (calculated by estimating the potential value or, subordinately, the prospective updated value of the expected benefits) and is entered for the first time in the assets of the statement of assets and liabilities, as a counter-item of an entry of the "other components of comprehensive income".

The report currently used in the preparation of financial statements does not allow an immediate overview of how dynamic value affected the financial report; therefore, the reader of the financial statements can't quantify the deviation due to earnings management in the context of the amount stated in the accounts.

As already seen, the unlawful practices of earnings management may have a better chance with dynamic assessments: the editor of the financial report would be forced to alter objective historical values, corresponding to the cost of purchase, or to alter the division of economic elements over time, with the immanent likelihood of being unmasked.

The empirical example shows that the matrix format is useful in informing stackeholders on the economic and financial position of the company, presenting each accounting item in its different parts that make it up.

Furthermore, the segregation provided by the matrix schema can also be useful in countering any phenomena that arise from earnings management, since it separates in a specific area those amounts subject to discretion.

The latter benefit can be seen especially when the matrix format is presented with several columns as it shows the evolution of the amounts of each accounting and segregates the "objective" amount from values that arise from conjecture

In the case suggested above, the reader of the accounts is promptly informed that the assets remesurement amounts to a total of 1,616.00 $€$ (over the different accounting items as shown in the table) and that the profits subject to discretionary redetermination are almost twice the profits determined on the basis of objective elements $(2.636 €$ instead of $1.440 €$ ).

Even so, the matrix format is obviously not the solution to all the earnings management problems: for example, it does not allow to counteract the representation of accounting fraud (with regard to the falsification of accounting records) or fraudulent transactions (for example, a transaction between two companies exclusively aimed at creating useful for an entity and losses for the other company); however, segregation of items in different columns allows the reader to have accounts purified from accounting estimates.

So will the reader, according to their preparation, decide whether to refer to the conjectures of the financial report's editor or, alternatively, base its assessment on objective data.

\section{Conclusions}

This study has tackled the question of adopting international accounting principles in view of the potential risks of an over-estimation of the income and the equity and, consequently, distortions in the information of the company that may derive from their application. The IAS/IFRS principles do not only keep account of the assets, liabilities and financial position inherited from the past, but also consider the present potentialities still to be realised and the prospective potentialities that will be realised in subsequent financial years. The dynamic evaluation methods imposed by the main international accounting principles have proven to be extremely useful for understanding the potential and future managerial activities. 
Stakeholders are increasingly interested in the financial and economic performances achieved during the financial year and in their future developments and it is for this reason that they require exhaustive, pertinent, reliable and timely information.

A growing number of companies is adopting dynamic evaluation methods and, consequently, it is becoming increasingly necessary to highlight the more volatile elements and the way in which they contribute towards the income. From the research carried out, it has emerged that this objective can be achieved by grouping together such components in a special section of the profit and loss account. This gives rise to the concept of Comprehensive Income, understood as a "new" profit and loss account, oriented towards the emergence of a "broadened" income compared with the traditional net income.

A correct evaluation of performance is essential for investors to enable them to decide whether to maintain, modify or cancel their investment; this explains the decision of the IAS/FASB to give greater relevance to the performance measurements calculated by means of the Comprehensive income instrument.

In fact, apart from the incomes that fall within the traditional profit and loss accounts, it also includes the changes in the net equity that do not derive from the shareholders' intervention and which, therefore, derive not only from financial or commercial transactions, but also from the variations in value produced by depreciations or revaluations. This "comprehensive income" enables the accounting data to be presented in a transparent and organic way and may be considered as a meeting point between the net income and variations in the assets and liabilities.

Apart from this, it has been noted that Comprehensive income may be considered as a valid measurement of the company's performance because, by including all the variations at fair value of the company's operations by third parties in the definition of income, it provides investors with additional information compared with the traditional net income. It is true that it was already possible to pinpoint the data regarding the "Other Comprehensive income" in other parts of the balance sheet, but by placing them in a special section it allows investors to recognise the aleatory elements and the potentialities inherent in the company more easily and immediately.

The representation of the income according to the Comprehensive income model seems to be essential for a proper structuring of the balance sheet and it is important for its very function of clarity, for the efficiency with which it groups together and isolates the "critical" income data and for its capacity to provide supplementary information on the performance of the company.

The Comprehensive income is, therefore, an essential element for presenting the income accounting data in a clear and transparent way. The objective of this instrument is not only a neat display of the income elements in order to provide stakeholders with better and clearer information, but also to guarantee the segregation of the same in order to make the readers of the balance sheet more aware of the aleatory nature of the results achieved and to prevent their evaluations from being modified by possible overestimates.

Amongst the advantages offered by this instrument, there is the richness of the information and the possibility of separating the dynamic adjustments from the accounting data, so as not to confuse or mislead the stakeholders. All of this must, however, be accompanied by an awareness on the part of the stakeholders themselves about the transience and aleatory nature of these elements. In fact, it must be borne in mind that the data contained in the Comprehensive income also refer to potential values and forecasts for the future calculated by means of discretional estimates and could be manipulated by the balance sheet compilers. This discretionary power to represent and evaluate is essential for calculating a correct financial year income, but it can also prove to be extremely dangerous. Indeed, widespread use is made today of "Earnings management" phenomena, in other words, the alteration of the accounting data for the purpose of influencing the choices made by the stakeholders.

Questions have, therefore, been raised regarding the appropriateness of this "new" profit and loss account as far as the presentation of accounting data is concerned and the representation of the actual company situation, in order to guarantee at the same time the significance, competence, prudence and comparability of the accounting information.

This consideration has given rise to the realisation that the simple use of the Comprehensive income does not solve any of the problems: and this, in our opinion, even if the comprehensive income is presented under matrix format.

For example, the traditional models of the statement of assets and liabilities does not reveal which part of the same is to be attributed to the income calculated using static methods and which, on the other hand, is attributable to variations in the balance sheet. Although it is a precious information instrument, the income statement matrix format is not, therefore, able to satisfy the requirements of the stakeholders by itself, and, in fact, if the dynamic methods of valuation are not compared with the static criteria, they run the risk of providing an excessively subjective view of the company's situation.

From this the need has emerged to associate its use with a representation of the balance sheet statements (formed from the balance sheet and income statement matrix format)which allows investors to gain more information about the past and future performance of the company: a representation offered by the "Matrix format" balance sheet.

The main innovation introduced by the matrix format is the segregation of the dynamic remeasurements of the accounts values in the "Remeasurement" column applied on the balance sheet that literature had not previously considered.

In the traditional balance sheet models based on international accounting principles, the value of the assets and liabilities subject to "Remeasurement" is entered at its fair value and the relative historical cost is shown in the 
notes; however, it could be more useful to readers of the balance sheet, as proposed by the Matrix format, to see both the values directly from the statement of assets and liabilities in order to gain a more immediate and instantaneous representation of the accounts.

Thanks to this balance sheet model, stakeholders can easily obtain information concerning the company's capacity to produce income by means of the operative income and the comprehensive income capacity of the same. Furthermore, the prospective income capacity of the company can be pinpointed thanks to the introduction, by means of dynamic evaluation methods, of income elements that have not yet been entirely realised and calculated.

The Matrix format allows additional information to be acquired about the past and future performance of the company by showing clearly the effects of using different accounting models for example, or there again by highlighting the consequences of using subjective data and measurements.

The format itself is very accurate and entails a very high level of transparency of the elements that it contains. All the information concerning the income elements (both realised and not) are grouped together in one single statement although they are separated from each other; as a result, it is easy to read and interpret, thanks, above all, to the presence of the "Remeasurement" column.

Although the representation is complex and costly, it also provides a quality and quantity of accounting information that no other type of balance sheet representation could offer. It offers information that is undoubtedly essential and which stakeholders must know how to use with caution.

Having considered that since the implementation of international accounting standard the complexity level of corporate structures has generally increased, the full matrix format analised by Tarca et alii can be a starting point for research for companies, economists and consulting professionals.

Use of the Comprehensive income and the Matrix format, therefore, allow not only the way the income has been formed to be illustrated but also the way in which it may evolve in the future by a projection of the management performances.

This type of approach leads to an improved representation of the company's performance and, in particular, an easier identification of the nature, amount and "weight" of the elements that have not yet actually been realised. It also allows an immediate and greater understanding as to whether these elements or those that have actually been realised have contributed more to the total income. Moreover, it can be used to show how the components that have not yet been realised vary in time.

In this context, the question was raised as to whether the combined use of the Comprehensive income and the Matrix format represent a valid measurement of a company's performance.

In the light of the results given by the analysis of literature and the results obtained from the two practical cases, it can be concluded that use of the Comprehensive income combined with the Matrix format represents a valid measurement of a company's performance as it ensures investors are given exhaustive information. It allows not only the way in which the income is formed to be illustrated, but also the way in which it may evolve in the future. In fact, in just one statement, but under separate columns, it includes the certain accounting data that have already been realised and the data that have not yet been realised and which are estimated or expected for the future, in order to provide stakeholders with a wider and thorough vision of the company, guaranteeing them maximum transparency.

From the analysis performed, it emerges that the values resulting from the representation in Matrix format based on the Comprehensive income are more representative of the real performance of the company, as they are not restricted just to the simple accounting data, but also consider the future possibilities that the company has, the opportunities offered by the context in which the company works and, consequently, a more complete vision of the company's actual situation.

Furthermore, this representation allows the influence that the prospective income items have on the final result to be shown; in fact, by segregating the prospective elements, the stakeholders can more easily obtain information about the future prospects of the company's performance without the risk of any illusions.

The examples given hereto must be further tested by extending the number of cases analysed. Moreover, any future work should concentrate on the "transformation"-"remeasurement" of the other balance sheet statements, for example the statement of income.

To conclude, the application of the dynamic accounting principles, based on fair value, presents undoubted advantages but, at the same time, at least one risk element: in fact, such principles contrast quite weakly with the "earnings management" phenomena as the qualitative and quantitative calculations are very complex and, consequently, they make it more difficult to identify the smoothing operations.

On the contrary, the accounting principles based on the historical cost lack information but are more objective in their calculation.

Having established the difficulty of resolving these problems, it is in any case considered worthwhile informing the stakeholders of the items that have undergone a greater degree of remesurement during the application of the dynamic accounting principles.

We believe that future research must first examine the segregation of the items of a dynamic nature, with a matrix format,for both the balance sheet and the income statement:: this will, undoubtedly, encourage a greater transparency in company information. 


\section{REFERENCES}

[1] SCHIPPER, K., "Commentary on «earnings management»", Accounting Horizons, December 1989, pgg. 91 - 102.

[2] BALL, R., BROWN, P., "An empirical evaluation of accounting income numbers", Journal of Accounting Research, volume 6, n. 2, 1968, pgg.159-178.

[3] HILTON A. S., O’BRIEN P. C., "Inco Ltd.: Market Value, Fair Value, and Management Discretion", Journal of Accounting Research, Vol. 47, n. 1, 2009, pgg. 179-211.

[4] HEALY P. M., WAHLEN J. M., "A Review of the «earnings management» Literature and Its Implications for Standard Setting", Accounting Horizons, Vol. 13, n. 4, 1999, pgg. 365-383.

[5] HEALY P. M., "The effect of bonus schemes on accounting decisions. Journal of Accounting and Economics", Vol. 7, 1985, pgg. $85-107$.

[6] WATTS R. L., ZIMMERMAN J. L., "Positive Accounting Theory: a Ten Year Perspective", The Accounting Review, volume 65 , n. 1, january 1990, pgg. $131-156$.

[7] BURGSTAHLER D., DICHEV I., “»earnings management» to avoid earnings decreases and losses", Journal of Accounting and Economics, vol. 24, 1997, pgg. $99-126$.

[8] BURGSTAHLER D., EAMES M., "Management of Earnings and Analysts' Forecasts to Achieve Zero and Small Positive Earnings Surprises", Journal of Business Finance \& Accounting, Vol. 33, num. 5 e 6, 2006, pgg. 633 - 652.

[9] HEALY P. M., WAHLEN J. M., "A Review of the «earnings management» Literature and Its Implications for Standard Setting", Accounting Horizons, Vol. 13, n. 4, 1999, pgg. 365-383.

[10] DEGEORGE F., PATEL J., ZECKHAUSER R., "«Earnings management» to Exceed Thresholds", Journal of Business, Vol. 72, n. 1, 1999, pgg. $1-33$.

[11] NELSON M, ELLIOTT J., TARPLEY R., "Evidence from Auditors About Manager' and Auditors' «earnings managem ent» Decisions.” Accounting Review. Supplement, 77, 2002, pgg. $175-202$.

[12] IASB, "Framework for the Preparation and Presentation of Financial Statements", 2001.

[13] BARKER L., "Reporting financial performance", Accounting Horizons, Vol. 18, n. 2, 2004, pgg. 157 - 172.

[14] Tarca A, Hancock P, Woodliff D, Brown P, Bradbury M, van Zijl T. Identifying Decision Useful Information with the Matrix Format Income Statement. Journal Of International Financial Management \& Accounting, June 2008;19(2):184217

[15] Tarca A, Brown P, Hancock P, Woodliff D, Bradbury M, van Zijl T. The Matrix Format Income Statement: A Case Study about Earnings Management and Reporting Financial Performance. Issues In Accounting Education, November 2007;22(4):607-623.

[16] Callao S, Jarne J. Have IFRS Affected Earnings Management in the European Union?. Accounting In Europe December 2010;7(2):159-189.

[17] Hamberg M, Paananen M, Novak J. The Adoption of IFRS 3: The Effects of Managerial Discretion and Stock Market Reactions. European Accounting Review, June 2011;20(2):263-288.

[18] Ljubicic M. Earnings Management and Accounting Choice: Expected Return on Pension Plan Assets under IAS 19 Empirical Evidence from Germany. Proceedings Of The Northeast Business \& Economics Association [serial online]. January 2010;:67-68. 